Research Institute of Animal Health, Assiut,

Director: Prof. Dr. S.M. Nashed.

\title{
PREVALENCE OF CAMPYLOBACTER AND SALMONELLA IN CATS AND DOGS (With One Table)
}

\author{
By \\ SABAH MOUSTAFA \\ (Received at 17/1/1989)
}

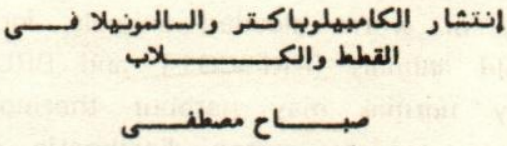

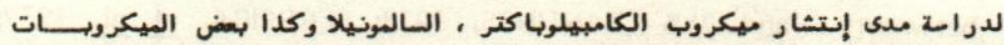

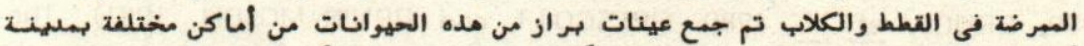

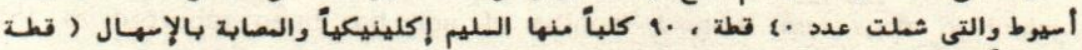

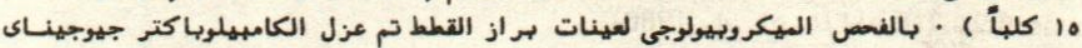

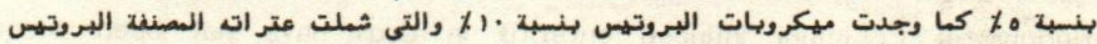

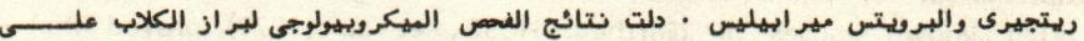

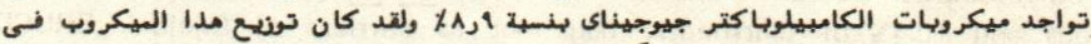

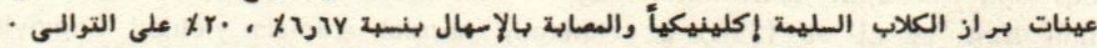

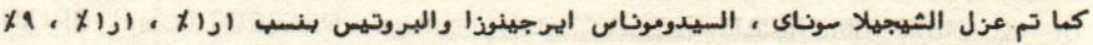

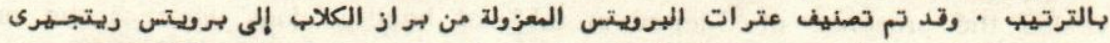

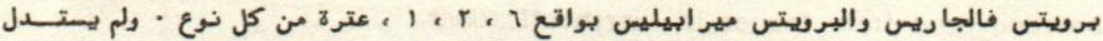

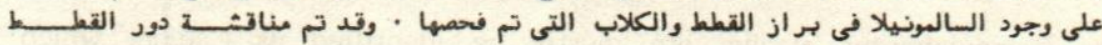

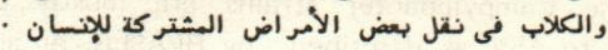

\section{SUMMARY}

Faeces were collected from normal and diarrheatic 130 pet animals (40 housed cats and 90 unknown dogs) for bacteriological studies on Campylobacter jejuni, Salmonella organisms and other enteric pathogens. Out of those pet animals one cat and 15 dogs showed signs of enteritis. Campylobacter jejuni and Proteus organisms were recovered from $5 \%$ and $10 \%$ of faeces of cats. The 4 Proteus strains were identified as Proteus rettgeri 2 and Protus mirabilis 2 while Campylobacter jejuni were isolated from $8.9 \%$ of the dogs used in this investigation. The organism was detected in $6.67 \%$ and $20 \%$ out of 75 clinically healthy and 15 diarrheatic dogs respectively. The recovery rates of Shigella sonnei, Pseudomonas aeruginosa and Proteus spp. were $1.1 \%$, $1.1 \%$ and $9 \%$ respectively. The identified Proteus spp. were Proteus rettgeri 6 , Proteus vulgaris 2 and Proteus mirabilis one. Salmonellae failed to be isolated from faeces of cats and dogs. The role of cats and dogs in transmission of some zoonotic agents was discussed. 


\section{SABAH MOUSTAFA}

\section{INTRODUCTION}

Some bacterial infections have been recognized as a zoonosis. Dogs and cats are considered the largest sources or focus of infection to man. It seems that Campylobacter like salmonellosis is an alimentary infectious disease (MORSE and DUNCAN, 1975; SVEDHEM and KAIJSER, 1981).

Campylobacter jejuni and Campylobacter coli have been encountered in the intestinal contents of a wide variety of warm blooded animals, including domestic species and free-living and captive wild animals (PRESCOTT and BRUIN-MOSCH, 1981). Dogs showed enteritis or apparently normal may harbour thermotolerant Campylobacter. The frequency of Campylobacter carriers among diarrheatic dogs has variably been reported to be between 1 and 75\% (HASTINGS, 1978; FERREIRA, et al. 1979; HOSIE, et al. 1979; BRUCE, et al. 1980; PRESCOTT and BRUIN-MOSCH, 1981). The rate of isolate C. jejuni in dogs less than 3 months of age has been reported as $35 \%$ and in older dogs as $8.9 \%$ (BLASER, et al. 1980).

Descriptions of $\mathrm{C}$. jejuni induced enteritis in dogs have not been adequate to rule out other known causes of diarrhea. HOSIE, et al. (1979) proved that 11.1\% of healthy dogs and $10.4 \%$ of diarrheatic dogs act as carriers of C.jejuni. BRUCE, et al. (1980) found that 15 of 38 (39\%) of clinically normal animals yielded Campylobacter, while 16 of 42 (38\%) diartheatic puppies were positive. PRESCOTT and BRUIN-MOSCH (1981) revealed the presence of C.jejuni in $0.5 \%$ of healthy dogs whereas the organism failed to be recovered from faeces of diarrheatic dogs.

Feline Campylobacter strains are mostly be identified as C.jejuni which ranging from few to $45 \%$ as described by BLASER, et al. (1980), BRUCE, et al. (1980), FLEMING (1983) and FOX, et al. (1983). However, KANEUCHI, et al. (1978) mentioned that 51 (6.6\%) of 593 cats had Campylobacter. BRUCE, et al. isolated the Campylobacter from $45 \%$ of 56 clinically normal cats. This higher condition may be due to some cats which were caught near poultry processing plant were scavenged contaminated food as processed poultry carcases are known to harbour Campylobacter.

Further studies on the prevalence of C.jejuni in pets demonstrated that the isolation rates of 13 to $75 \%$ for puppies, 5 to $50 \%$ for dogs and 4 to $10 \%$ for cats have been reported by HASIINGS (1978), BLASER, et al. (1979), FERREIRA, et al. (1979) and HOSIE, et al. (1979). Moreover, the incidence of campylobacter isolation from dogs nad cats recorded by SVEDHEM and KAIJSER (1981) was about $5 \%$.

Many investigators studied the transmission of canine Campylobacter from dogs and puppies to man (SKIRROW, 1979 and BLASER, et al. 1978) as well as the transmission from pets cats to man (SKIRROW, et al. 1980; SVEDHEM and NORKANS, 1980 and BLASER, et al. 1982).

Salmonella is considered as pathogenic bacteria of considerable medical and economic interest. ADLER, et al. (1951), GORHAM and GARNER (1951), VARLEA, et al. (1951), SHOUMAN, et al. (1979), LOTFI and NASHED (1980) which were isolated Salmonella 


\section{ZOONOTIC PATHOGENS IN CATS AND DOGS}

spp. from diseased and healthy dogs. However, MURDOCH (1986) stated that Salmonella spp. are frequently isolated from the faeces of normal cats and dogs and rarely cause clinical disease in adults while in young cats and dogs salmonellosis can be fatal. Salmonella was harboured in dogs and cats and transmission of Salmonella to human from pet animals has been demonstrated by MORSE and DUNCAN (1975), KOTANI, et al. (1977), FKUSHIMA, et al. (1985) and KANEUCHI, et al. (1987).

Dogs and cats are also a possible source of enteropathogenic organisms. Pseudomonas aeruginosa was isolated from two fatal cases of haemorrhagic enteritis in dogs while Proteus spp. appeared to be members of the normal intestinal flora of dogs (GORHAM and GARNER, 1951). However, CRAIGE (1948) and (1950) pointed out that Proteus organisms are an aetiologic agent of acute and chronic dysentry in dogs. Furthermore, VARELA, et al. (1951) reported the presence of shigella in dogs.

Since dogs and cats live in close contact with man, the elimination of pathogenic microorganisms from its intestines is an important consideration in the epidemiology of human enteric infections. Therefore, this study was undertaken to clarify the significance of dogs and cats in Upper Egypt as reservoirs of C.jejuni, Salmonella and some enteric pathogens.

\section{MATERIAL and METHODS}

Rectal swabs and faecal specimens were collected from a total of 130 dogs and cats ( 40 housed cats from various sources and 90 stray dogs brought to Faculty of Vet. Med. Hospital, Assiut University). All animals were apparently healthy except one cat and 15 dogs showed signs of enteritis. Microbial analysis of faecal samples for

the presence of Campylobacter, Salmonella and other enteric pathogens was carried out.

Isolations of Campylobacter were made by direct and enrichment culture methods. Each sample was plated onto blood agar base supplemented with $5 \%$ human defibrinated blood, vancomycin $5 \mathrm{mg} /$ liter, trimethoprium $2.5 \mathrm{mg} / \mathrm{liter}$ and polymxin B 1.250 IU/liter (ROGOL, et al. 1985). These samples were also inoculated into ROSEF (1981) liquid enrichment medium supplemented with vancomycin $10 \mathrm{mg} / \mathrm{liter}$, trimethoprium $5 \mathrm{mg} /$ liter and polymxin B $2500 \mathrm{lU} /$ liter. Both media were incubated at $42^{\circ} \mathrm{C}$ for 48 $\mathrm{h}$ under microaerophilic condition in anaerobic jar without catalyst using Campylobacter generatign gas kits (Oxoid). All the seeded plates were examined after $48 \mathrm{~h}$ of incubation for small, flat, grey or mucoid colonies which when examined by Gram stain showed characteriostic Gram-negative spiral or S-shaped organisms. All enrichment media were subcultured on solid selective plates as described before. Biochemical characteristics of Campylobacter isolates were tested according to the recommended methods described by PARK, et al. (1984).

Isolation of Salmonella spp. and other enteric pathogens was done by direct plating of faecal samples on Salmonella-shigella (SS) agar plates. Also, samples were secondarily plated onto SS agar plates after incubation in selenite cystine broth at $37^{\circ} \mathrm{C}$ for 24

Assiut Vet.Med.J. Vol.22, No. 43, 1989. 


\section{SABAH MOUSTAFA}

h. The agat plates were incubated at $37^{\circ} \mathrm{C}$ for $24 \mathrm{~h}$. Typical colonies were checked for biochemical characteristics by using the API $20 \mathrm{E}$ (Analytab Products, Plainview New York, USA) and serological characteristics by standard procedures outlined by BAILEY and SCHOTT (1974) and CRUICKSHANK, et al. (1975) was followed for identification of Salmonella organisms.

Furthermore, Pseudomonas agar base supplemented with SR 103 (Oxoid) was used for isolation of Pseudomonas aeruginosa.

\section{RESULTS}

Results presented in Table (1) demonstrated the isolation rates of C.jejuni and some enteric pathogens from the faeces of cats and dogs.

\section{DISCUSSION}

The prevalence of Campylobacter and Salmonella in cats have rarely been conducted in comparison with those in other animals. All the cats used in this study were household and seemed to be healthy pet cats. The carrier rate of the zonotic agent of Campylobacter in cats is relatively low.

Campylobacter jejuni ranging from 2 to $45 \%$ have been reported in cats of various sources by BLASER, et al. (1980), BRUCE, et al. (1980); FLEMING' (1983); FOX, et al. (1983 a) and KANEUCHI, et al. (1987). In this study the occurrence of Campylobacter in 5\% of the examined cats is among the intermediate reported. The same recovery rate of C.jejuni from cats was recorded by SVEDHEM and KAIJSER (1981). On the other hand FOX, et al. (1983 b) could not able to isolate the organism from cats, while a $2 \%$ incidence ever reported for the apparently healthy pet cats was demonstrated by GRUFFYDD-JONES, et al. (1980). Moreover, MURDOCH (1986) stated that Campylobacter is frequently isolated from the faeces of normal cats.

Salmonella failed to be detected in faeces of cats. In this respect, isolations of Salmonella fromt the cat are uncommon where GORHAM, et al. (1951) could not able to isolate the organism from the faeces of 91 cats. On the contrary, Salmonella organisms were present in 8 of $593(1.3 \%)$ of the examined cats. However, some investigators reported the isolation of Salmonella organisms from cats and the recovery rate varied from 1 to 10.8\% (BALL, 1954; SHIMI and BARIN, 1977, FOX and BEAUCAGE, 1979).

Cats have close relations to humans as one of the most popular pet animals and be regarded as a significant reservoir of some zoonotic agents.

The incidence of Campylobacter in dogs ranged from 0.5 to $50 \%$ as reported by BLASER, et al. (1979); FERREIRA, et al. (1979); HOSIE, et al. (1979) and PRESCOTT, et al. (1981). The result showed that faeces from 90 dogs examined yielded $8.89 \%$ campylobacters. However, of a total of 90 dogs examined for the presence of Campylobacter, 75 clinically normal animals yielded 5 positive (6.67\%) and 3 of $15(20 \%)$ diarrheatic dogs were positive for C.jejuni.

Assiut Vet.Med.J. Vol.22, No. 43, 1989. 


\section{ZOONOTIC PATHOGENS IN CATS AND DOGS}

FUKUSHIMA, et al. (1985) reported an incidence of $4 \%$ in dogs, while SVEDHEM and KAIJSER (1981) revealed that the carrier rate of C.jejuni in dogs was 5\%. These results seemed to be lower than the obtained results.

An association between infected wogs and human campylobacterasis has been recently noted by SKIRROW (1977); BLASER, et alo (1978) and BRUCE, et al. (1980). BLASER, et al. (1982) reported that healthy puppies excretel. C.jejuni more frequently than adult dogs and that the puppies with diarrhea appear to be especially important in the transmission of the disease to humans. BRUCE, et al: (1980) revealed that a diarrheatic puppy in asociation with two children was excreting the organism for 40 days after the onset of the boy's illness.

Many investigators reported the isolation of salmonellae from faeces of dogs and the failure of recovery of such organisms may be due to the competitive effect of other intestinal flora. However, Proteus organisms were detected in $9 \%$ of dogs whereas the isolation rates of Shigella sonnei and Pseudomonas aeruginosa were the same (1.1\%).

GORHAM, et al. (1951) observed that Proteus does appear in a high percentage of normal and sick dogs and they believe that Proteus spp. are part of the normal intestinal flora of dogs. On the other hand, Pseudomonas aeruginosa was recovered from two cases of haemorrhagic gastroenteritis. Furthermore, Shigella sonnei was detected in $2 \%$ of the dogs studied by VARLEA, et al. (1951).

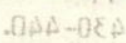

Our results indicated that cats and dogs may act as a reservoir of some zoonotic pathogens and the public should therefore be made aware of the potential hazards associated with infections transmitted by pet animals.

\section{REFERENCES}

Adler, H.E.; Willers, E.H. and Levine, M. (1951): Incidence of Salmonella in apparently healthy dogs. J. Am. Vet. Med. Assoc. 118: 300.

Bailey, W.R. and Scott, E.G. (1974): Diagnositic Microbiology. A text book for the isolatCompany, Saint Louis.

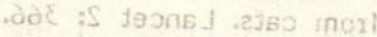

\section{ion and identification of pathogenic microorganisms. 4 th Ed. The G.V. Mosby}

Ball, R. (1954): Salmonella in dogs and cats of the Los Angeles, Honolulu, and Bermuda areas. J. Am. Vet. Med. Assoc. 118: 164-166.

Blaser, M.J. Cravens, J.; Poweres, B.W. and Wang, W.I. (1978): Campylobacter enteritis associated with canine infection. Lancet 11: 979-981.

Blaser, M.J.; Laforce, F.M.; Wilson, N.A. and Wang, W.L.L.A (1980): Reservoirs for human campylobacteriosis. J. Infect. Dis. 141: 665-669.

Blaser, M.; Roesler, P.; Hardesty, H.E. and Wang, W.L. (1979): CDC Veterinary Public Health Notes. February 6-7. Cited by Bruce, et al. (1980).

Blaser, M.J.; Wein, S.H. and Barrett, T.J. (1982): Campylobacter enteritis associated with a healthy cat. J. Am. Vet. Med. Assoc. 24: 816.

Bruce, D.; Zochowski, W. and Fleming, G.A. (1980): Campylobacter jejuni in cats and dogs. Vet. Rec. 109: 200-201.

Assiut Vet.Med.J. Vol.22, No. 43, 1989. 


\section{SABAH MOUSTAFA}

Craige, J.E. (1948): Proteus organisms infecting dogs. J. Am. Vet. Med. Assoc. 113: 154-155.

Craige, J.E. (1950): Diagnosis and treatment of dysentry in dogs. Vet. Med. 45: 55-56. Cruickshank, R.; Dugid, J.P.; Marmion, B.P. and Swain, R.H.A. (1975): Medical Microbiology. 12th Ed. Churchill Livingstone. Edinburg, London, New York.

Ferreira, M.C.S. Ribeiro, V.L.S. and Ricciardi, J.D. (1979): Campylobacter dogs and human enteritis. Vet. Rec. 105: 451.

Fleming, M.P. (1983): Association of Campylobacter jejuni with enteritis in dogs and cats. Vet. Rec. 113: 372-374. Fox, J.G. and Beaucage, C.M. (1979): The incidence of Salmonella in random-source
cats purchased for use in research. J. Infect. Dis. 139: 362-365.

Fox, J.G.; Moore, R. and Ackerman, J.l. (1983 a): Canine and feline campylobacterosis epizootiology and clinical and public health features. J. Am. Vet. Med. Assoc. 183: $1420-1424$.

Fox, J.G.; Moore, R. and Ackerman, J.I. (1983 b): Campylobacter jejuni-associated diarrhea in dogs. J. Am. Vet. Med. Assoc. 183: 1430-1433.

Fukushima, H.; Nakamura, R.; Itsuka, S.; Ito, Y. and Saito, K. (1985): Presence of zoonotic pathogens (Yersinia spp., Campylobacter jejuni, Salmoneila spp., and Leptospira spp.) simultaneously in dogs and cats. Zbl. Bakt, Hyg., I. Abt. Orig. B 181: 430-440.

Gorham, J.R. and Carner, F.M. (1951): The incidence of Salmonella infections in dogs and cats in a nonurban area. Am. J. Vet. Res. 12: 35-37.

Gruffydd-Jones, T.J.; Marston, M. and White, E. (1980): Campylobacter jejuni enteritis from cats. Lancet 2: 366.

Hastings, D.H. (1978): Campylobacter enteritis in pets. Lancet 11: 1249-1250.

Hosie, B.D.; Nicholson, T.B. and Henderson, D.B. (1979): Campylobacter infections in normal and diarrheatic dogs. Vet. Rec. 105: 80-81.

Kaneuchi, C.; Shishido, K.; Shibuya, M.; Yamaguchi, Y. and Ogata, M. (1987): Prevalences of Campylobacter, Yersinia, and Salmonella in cats housed in an animal protection center. Jpn. J. Vet. Sci. 49: 499-506.

Kotani, T.; Fukuda, M.; Ucbida, A.; Muku, T.; Kameie, R. and Sugimura, K. (1977): Human infection with Salmonella typhimurium associated with a household cat. J. Jpn. Vet. Med. Assoc. 30: 119-120.

Lotfi, Z.S. and Nashed, S.M. (1980): Salmonella infection in dogs. Agriculture Research Review 7: 117-122.

Morse, E.V. and Duncan, M.A. (1975): Canine Salmonellosis prevalence, epizootiology, signs and public health significance. J. Am. Vet. Med. Assoc. 167: 817-820.

Murdoch, D.B. (1986): Diarrhea in the dog and cat. I. Acute diarrhea. Br. Vet. J. 142: 307-316.

Park, C.E.; Simbert, R.M.; Blaser, M.J.; Vanderzant, C.V. and Stern, N.J. (1984): Campylobacter. In the compendium of Methods for the Microbiological Examination of Foods. 2nd Ed. Speck, M.L. (ed). Washington, D.C. American Public Health Association. 


\section{ZOONOTIC PATHOGENS IN CATS AND DOGS}

Prescott, J.F. and Bruin-Mosch, C.W. (1981): Carriage of Campylobacter jejuni in healthy and diarrheatic animals. Am. J. Vet. Res. 42: 161-165.

Rogol, M.; Shpak, B.; Rothman, D. and Sechter, I. (1985): Enrichment medium for isolation of Campylobacter jejuni-Campylobacter coli. Appl. Environ. Microbiol. 50: $125-126$.

Rosef, O. (1981): Isolation of Campylobacter fetus subsp. jejuni from the gall bladder of normal slaughter pigs using an enrichment procedure. Acta Vet. Scand. 22: 149-151.

Shimi, A. and Barin, A. (1977): Salmonella in cats. J. Comp. Pathol. 87: 315-318.

Shouman, M.T.; Fawzy, F.G. and El-Gibaly, S.M. (1979): Preliminary investigation on stray dogs as carriers for pathogenic E.coli, Salmonella and Shigella. 14th Arab Vet. Med. Congress, Cairo, Egypt.

Shirrow, M.B. (1977): Campylobacter enteritis: a "new" diseas. British Medical J. 2: 9-11.

Skirrow, M.B.; Turnbull, H.L.; Walker, R.E. and Young, S.E.J. (1980): Campylobacter jejuni enteritis transmitted from cat to man. Lancet 1: 1188.

Svedhem, A. and Kaijser, B. (1981): Isolationof Campylobacter jejuni from domestic animals and pets. Probable origin of human infection. J. Infection, 3: 37-40.

Svedhem, A. and Norkans, G. (1980): Campylobacter jejuni enteritis transmited from cat to man. Lancet 2: 713-714.

Tanaka, Y.; Katsube, Y. and Imaizumi, K. (1976 a): Distribution of Salmonella in the digestive tract and lymph node of carrier-dogs. Jpn. J. Vet. Sci., 38: 215-224.

Tanaka, Y; Katsube, Y. and Imaizumi, K. (1976 b): Experimental carrier dogs produced by oral administration of Salmonella typhimurium. Jpn. J. Vet. Sci., 38: 569-578.

Varlea, G.; Perez-Rebelo, R. and Olarte, J. (1951): Salmonella and Shigella organisms in the intestinal tracts of dogs in Mexico City. J. Am. Vet. Med. Assoc. 119: 385-386.

Table (1)

MPN count of C-perfringens in Fish and Mollusks

\begin{tabular}{llcrc}
\hline Oryanism & \multicolumn{2}{c}{ Cats } & \multicolumn{2}{c}{ Dogs } \\
\cline { 2 - 5 } & $\begin{array}{c}\text { No. } \\
\text { examined }\end{array}$ & $\begin{array}{c}\text { No. } \\
\text { positive } \\
(\%)\end{array}$ & $\begin{array}{c}\text { No. } \\
\text { examined }\end{array}$ & $\begin{array}{c}\text { No. } \\
\text { positive } \\
(\%)\end{array}$ \\
\hline $\begin{array}{l}\text { C. jejuni } \\
\text { Shigella sonnei }\end{array}$ & 40 & $2(5 \%)$ & 90 & $8(8.89 \%)$ \\
Pseud. Aeruginosa & 40 & 0 & 90 & $1(1.1 \%)$ \\
Proteus spp. & 40 & 0 & 90 & $1(1.1 \%)$ \\
& 40 & $4(10 \%) *$ & 90 & $9(10 \%) * *$ \\
\hline
\end{tabular}

Assiut Vet.Med.3.Vol. 22, No. 43, 1989. 